Loperfido G. (2018). "What Can Anthropology Say About Populism?" Anthropology News. March 19, 2018. DOI: 10.1111/AN.801 https://anthrosource.onlinelibrary.wiley.com/doi/abs/10.1111/AN.801

\title{
What Can Anthropology Say about Populism?
}

\author{
Giacomo Loperfido
}

In a recent article in Anthropology News, Víctor Giménez Aliaga suggests that the contemporary wave of populism calls for closer anthropological analysis of the term and its usages. While it is less interesting to me to partake in the eternal strive to define "what populism means," I concur with Giménez Aliaga with the need for anthropology to asses "practices - that is, the ways and purposes with which the term is used in the political arena. In response to Gimenéz Aliaga's call, I will try to sketch out some of the insights an anthropological perspective could provide around current political transformations.

The stigmatized categories of immigrants, or intraclass competitors are often categorized as just a result of the malfunctioning of the state, or-worse-of its malicious will.

\section{The problem with the left}

A common feature stands out if we look at the global political situation: the left suffers an historical identity crisis. Where the left fails in representing instances from the lower segments of the social ladder, the populist right moves on to occupy the ideological terrain evacuated by its adversaries ( $\underline{\text { Zizek 2000)}}$ ). Left-wing parties, on the other hand, seem to have become the major political/institutional infrastructure of "the middle classes.” But the middle classes also operate as an ideological horizon of aspirations and values, something that is not defined by the opposition of its interests to those of other social groups (Zizek 2009). In this sense, it ends up working as a representational device enhancing the idea of a socially uniform and conflict-free society (Guilluy 2010; Palomera, personal exchange 2017), repressing class distinctions and the conflicts that these generate. Nevertheless, if the left has appeared for a while successful in championing this vision, it has now become evident that the negation or repression of class cleavages and class conflicts in the political sphere was a losing strategy in the long run. The middle class's anxiety about losing status and resources has backfired against the left, which appears increasingly bewildered, self-referential, and unable to govern current social and economic turmoil.

Moreover, the negation or repression of the political representation of different orders of interests organized by the class paradigm, has led to moral re-articulation of social/political divides and morally 
informed dichotomies such as deserving vs. undeserving, “la casta” vs. "the indignant”, the 1 percent vs. the 99 percent (Zizek 2008, Kalb 2011, MouQe 2005, Crouch 2000).

\section{Politics embodied}

There seems to be a trend towards the personalization of politics. From Italy ( showing populist features) to the United States (Trump, Clinton), and in the burgeoning anti-EU scene (from right to left, Le Pen, Farage, Salvini, Iglesias, Tsipras, or Varufakis vs. the Troika), charismatic leaders have emerged in popular representations, cast as the heroes and anti-heroes who are supposed to personify the struggle of diverse social projects competing over the control of society. This trend naturalizes processes of political dispossession on the one hand, and the struggles to resist those processes on the other. It also obscures the structural dynamics from which the same leaders seem both a product and a metaphor. The resulting double trend of scapegoating is directed against elites or the abstracted state upward and against immigrants and intraclass competitors downward. This combined logics of intraclass differentiation and embodiment, appear to merge into an almost Dumontian comeback to a hierarchical vision of society, where egalitarian assumptions are implicitly denied and difference is essentialized.

\section{Social chaos and the demagogue}

The lack of representation or political recognition of lower classes, together with what one might call the collapse of the middle class dream, seem to entail a pervasive diffusion of fears touching upon the loss of power, status, wealth, or social recognition. In addition, a socially transversal discontent with the functioning of the state seems to have brought the latter to change its position within the cosmological representation of contemporary Western societies. The parliamentary systems are increasingly less the place where conflicts among different segments of society are negotiated and are on their way to becoming one among many subjects of political antagonism: just another political adversary to oppose. In fact, the stigmatized categories of immigrants, or intraclass competitors are often categorized as just a result of the malfunctioning of the state, or-worse-of its malicious will. Overall, these aspects seem to announce a general collapse of established sociological and politological categories. Consequently, social principles lose their capability to operate as axioms for social behavior. This is above all true in current political life, where long established moral and political predicaments no longer appear to govern projects of electoral and political solidarity. Voters of Syriza in Greece announced last year that they would vote Golden Dawn (“if this doesn’t work out”), and Trump supporters have declared they would have voted for Sanders. 
This chaotic space is exploited by demagogues. They systematically foster and organize the political fallout of economic, social, and psychological distress at the same time that they deliberately obstruct the machinery of political conciliation. It is by inhabiting this space of contradiction that new political agent provocateurs manage to arouse gross quantities of affect, often raising upside down, carnivalesque, erotic imageries (think of Berlusconi, Fortuyn, Kirchner, Trump). They release, in this way, the necessary social energy for breaking bonds and ties of long-established social or political solidarities. It is this "totalitarian" pressure imposed by the faltering of actual systems, which brings together diverse segments of society in revolt against the institutional order that we tend to term "populism."

Giacomo LoperQdo, holds a PhD in social anthropology from École des Hautes Études en Sciences Sociales and the Università degli Studi di Bergamo. He is ERC Researcher in social anthropology for GRECO (Grassroots Economics Project: Meaning, Project and Practice in the Pursuit of Livelihood) at the University of Barcelona. His research explores questions of political violence, political radicalism, cultural enclavization, and socio-economic disintegration in the context of global-systemic crisis. 